\title{
A Comparative Study of Psychological Capital in Government and Private Hospital Doctors
}

\author{
Evelyn Raghel Thomas ${ }^{1}$ and Geetika Tankha ${ }^{2}$ \\ ${ }^{1}$ Research Scholar, Department of Psychology, Manipal University Jaipur, \\ Jaipur, Rajasthan, India \\ ${ }^{2}$ Professor, Department of Psychology, Manipal University Jaipur, \\ Jaipur, Rajasthan, India
}

\begin{abstract}
The aim of the current study was to investigate the effect of psychological capital and its components i.e. hope, efficacy, resilience and, optimism in the sample of 150 doctors working in Private and Government hospitals of Jaipur City. A socio demographic proforma and PCQ - 24 (Luthans, Avolio and Avey, 2007) were used to measure PsyCap and its components respectively. Statistical analysis was conducted using descriptive statistics (Mean, Standard deviation) and inferential statistics (Independent $\mathrm{t}$ - test). The obtained results suggested that doctors working in government hospital emerged to be higher on overall PsyCap and its four dimensions, furthermore, government hospital doctors have a higher level of resilience with respect to other components of PsyCap. Implications of these findings are discussed.
\end{abstract}

Keywords: PsyCap, Hope, Resilience, Efficacy, Optimism, Health professionals

\section{Introduction}

The profession of a doctor is considered to be the most stressful career profession. This is because of its long and laborious working hours, patient expectations, the huge number of patients etc. Researchers have suggested that work stress leads to the negative outcomes such as high staff turnover, increased level of absenteeism and low morale among employees (Kivimaki, Vahtera, Pentti, and Ferrie, 2000). Therefore, interventions implemented in the field of positive psychology, especially the development of PsyCap as a positive resource has shown to be effective in alleviating negativity and increase positivity among work environment (Sin \&
Lyubomirsky, 2009). The concept of PsyCap originated under the concept of positive organizational behavior. Positive organizational behavior refers to the application of potential human strength or capacities that can be effectively managed and developed to reinforce a healthy work environment (Luthans, 2002b).

Psychological Capital or PsyCap is defined by positive organizational behavior as an intervention model for employees and organization (Luthans \& Youssef, 2004). PsyCap is constituted by four components i.e. hope, efficacy, resilience and, optimism which are measurable and open to development. Efficacy refers to one's self confidence and the ability to perform any task. Hope refers to the positive motivational state in the path of achieving one's goal. Resilience is defined as bouncing back in the time of adversity or suffering. Optimism refers to positive self - attribution towards any task. Over the years, researchers have concluded that there is a need for developing these positive human strengths so that the work stress can be reduced and the productivity can be increased in the workplace. With respect to the Indian context, there is a dearth of research on Psycap on doctors, therefore the present study was carried out to examine the effect of PsyCap on the type of organization i.e. Private and Government hospital among doctors.

During the past decade, longitudinal studies have suggested that PsyCap tends to change over time (Avey et al. 2010, Peterson et al. 2012). Researchers have also suggested that PsyCap can be developed and worked upon to change effectively through training programs and small - scale interventions 
(Dello, Russo \& Stoykova 2015; Demerouti et al. 2011; Ertosun et al. 2015; Luthans et al. 2006a, 2008b, 2010, 2014).

Research on the effect of PsyCap on health professionals is limited. Avey, Luthans and, Jensen (2009) found that individuals with low levels of PsyCap are vulnerable to stressful symptoms and exhibit unsatisfactory job performance. Hence, it is important to identify and develop the level of PsyCap among doctors pertaining to stress level in their job. Li Liu, Ying Chang, Jialiang Fu, Jiana Wang and Lie Wang (2010) conducted a study to explore the mediating properties of PsyCap between occupational stress and depressive symptoms among 998 Chinese physicians. The results recommended that an individual's work reward, over commitment, was associated with depression. The positive nature of PsyCap is associated with positive emotions (Fredrickson, 2001, 2009) and higher creativity (Sweetman et al. 2011) which will contribute to alleviating negative emotions in the workplace. PsyCap also facilitates well - being as reported in a conceptual framework by Youssef - Morgan \& Luthans (2015).

In the light of above concerns, the present study aims to investigate the effect of PsyCap among doctors with respect to their institutional affiliation i.e. Private and Government hospital.

\section{Materials and Methods}

\subsection{Sample}

This study comprised of 150 (75 Government hospital and 75 Private hospital) doctors of Jaipur city in the age range of 35 to 55 years.

\subsection{Materials}

\subsubsection{Proforma: -}

Information about the socio demographic details such as age, gender, years of experience, type of organization were obtained who participated in the survey.

3.2.2 Psychological Capital Questionnaire - 24 (Luthans, Youssef \& Avolio, 2007): -

This scale was used to measure the overall PsyCap and its dimensions i.e. hope, efficacy, resilience and optimism respectively. The PCQ -24 is a self report questionnaire which consists of 24 items and each subscale of six items. It is 6 point likert scale and the resulting score represents an individual's level of PsyCap.

\subsubsection{Procedure: -}

Participants were recruited from the Private and Government hospitals of Jaipur city. The profroma and the PsyCap questionnaire were administered among 150 respondents after taking their informed consent. Proper instructions were given to the respondents before administration of the scale. Furthermore, for statistical analysis, SPSS version 21 was used for both descriptive statistics i.e. mean, standard deviation and inferential statistics i.e. $t-$ test for the data.

\section{Results}

Table 4.1 lists the means and standard deviations of the study variables i.e. PsyCap and its dimensions (hope, efficacy, resilience and optimism) in government and private hospital respectively. The obtained means show that government doctors have higher scores in overall PsyCap $(\mathrm{M}=4.90$, S.D $=.323)$, hope $(M=4.93$, S.D = .416), efficacy $(M=$ 4.88, S.D. $=.268)$, resilience $(\mathrm{M}=5.02, \mathrm{~S} . \mathrm{D}=.384)$ and optimism $(\mathrm{M}=4.90, \mathrm{~S} . \mathrm{D}=.372)$ in comparison to private hospital doctors.

Table 4.2 depicts the independent sample $\mathrm{t}$ - test for the sample of 150 doctors. The results clearly suggested that government hospital doctors have statistically higher PsyCap $(4.90 \pm .323)$ as compared to PsyCap in Private hospital doctors (4.71 $\pm .319), \mathrm{t}(148)=3.634, \mathrm{p}=.000)$ respectively.

With respect to the dimension of efficacy, the scores were statistically significant which indicated that the government doctors were more self - efficacious $(4.88 \pm .268)$ in comparison to private doctors $(4.67$ $\pm .265), \mathrm{t}(148)=4.682, \mathrm{p}=.000)$.

On the dimension of resilience, the results showed that the government hospital doctors were found to be more resilient $(5.02 \pm .384)$ as compared to Private hospital doctors $(4.86 \pm .360), \mathrm{t}(148)=$ 2.538, $\mathrm{p}=.012$ ).

A statistically significant scores were obtained on the dimension of hope which indicated that the government hospital doctors were found to be more hopeful $(4.93 \pm .416)$ as compared to Private hospital doctors $(4.78 \pm .424), \mathrm{t}(148)=2.060, \mathrm{p}=.041)$. 
On the dimension of optimism, the results were statistically significant and showed that the government hospital doctors were found to be more optimistic $(4.90 \pm .372)$ as compared to private hospital doctors $(4.68 \pm .351), \mathrm{t}(148)=3.593, \mathrm{p}$ $=.000)$.

Table 4.1 Means and standard deviation of the sample of doctors

\begin{tabular}{|c|c|c|c|c|}
\hline S.No. & Variables & $\begin{array}{c}\text { Type of } \\
\text { organization }\end{array}$ & Mean & S.D \\
\hline \multirow[t]{2}{*}{1} & PsyCap & $\begin{array}{c}\text { Government } \\
\text { hospital }\end{array}$ & 4.90 & .323 \\
\hline & & $\begin{array}{l}\text { Private } \\
\text { Hospital }\end{array}$ & 4.71 & .319 \\
\hline \multirow[t]{2}{*}{2} & Hope & $\begin{array}{c}\text { Government } \\
\text { hospital }\end{array}$ & 4.93 & .416 \\
\hline & & $\begin{array}{c}\text { Private } \\
\text { Hospital }\end{array}$ & 4.78 & .424 \\
\hline \multirow[t]{2}{*}{3} & Resilience & $\begin{array}{c}\text { Government } \\
\text { hospital }\end{array}$ & 5.02 & .384 \\
\hline & & $\begin{array}{l}\text { Private } \\
\text { Hospital }\end{array}$ & 4.86 & .360 \\
\hline \multirow[t]{2}{*}{4} & Efficacy & $\begin{array}{c}\text { Government } \\
\text { hospital }\end{array}$ & 4.88 & .268 \\
\hline & & $\begin{array}{c}\text { Private } \\
\text { Hospital }\end{array}$ & 4.67 & .265 \\
\hline \multirow[t]{2}{*}{5.} & Optimism & $\begin{array}{c}\text { Government } \\
\text { hospital }\end{array}$ & 4.90 & .372 \\
\hline & & $\begin{array}{c}\text { Private } \\
\text { Hospital }\end{array}$ & 4.68 & .351 \\
\hline
\end{tabular}

Table 4.2 Independent Sample $\mathrm{t}$ - test of the sample of doctors

\begin{tabular}{|c|c|c|c|}
\hline S.No. & Variables & t value & Sig. \\
\hline 1 & PsyCap & 3.634 & .000 \\
\hline 2 & Hope & 2.060 & .041 \\
\hline 3 & Resilience & 2.538 & .012 \\
\hline 4 & Efficacy & 4.682 & .000 \\
\hline 5. & Optimism & 3.593 & .000 \\
\hline
\end{tabular}

\section{Discussion}

The main objective of this study was to examine the effect of overall PsyCap and its components (hope, efficacy, resilience and optimism) on the type of organization i.e. private and government hospital among doctors.

With reference to the findings of this study, it was observed that the group of doctors working in government hospital emerged to be supreme on comparing profiles of overall PsyCap and its four components i.e. hope, resilience, efficacy and optimism in comparison to doctors working in private hospital. Similar findings were reported in the study by Shahnawaz and Jafri (2009) which suggested that PsyCap was significantly different with reference to type of organizations i.e. Private and Public sectors. On the other hand, a contrast findings were reported by a study conducted by Choubsia (2009) which suggested that private employees were having high level of PsyCap and its dimensions as compared to government employees.

With respect to the obtained means on the dimension of resilience, the doctors of government hospital were more resilient than doctors of private hospital which suggests that the processes and dynamic structure within the government hospital provides the doctors with a competitive environment, hence equipping them to withstand challenges in the workplace. Similar findings were reported by Everly (2011) which stated that the processes of an organizational resilience can be developed and managed by employees at all levels in the time of adversity.

The findings also suggested that doctors working in government hospital were hopeful, self - self efficacious and optimistic in their pursuits. The present finding is consistent with the earlier study conducted by Eid, Mearns, Larsson, Laberg \& Johnsen (2012) which stated that in hospitals, employees are self - confident as they are trained with the necessary skills and knowledge required to understand the risk and potential hazards associated with work operations. Similarly, Llewellyn, Sanchez, Asghar and Jones (2008) also reported that individuals with high self - efficacy prefer to opt for laborious, tedious tasks as they recognize their potential and have higher hope (Snyder, 2000).

The findings of this study was that the doctors in government hospital are better performers. The factors responsible for this can be many such as high income, number of cases handled in a day or shifts, family support etc. it clearly indicates that there is a lack of incentive and huge work pressure in doctors working in private sector. Therefore, it can be recommended that there should be training workshops for promoting wellness and implementing applications of positive psychology in both individual and organizational level. 
The limitations of this study is that the data collected is based on subjective evaluations of doctors and is restricted to small sample size.

The study highlights the need to explore the determinants and factors of PsyCap and impact of organizational culture on different groups of specializations under the purview of health professionals in the view of promoting stress management and mental health well - being in the field of medicine.

\section{Conclusions}

The findings of the present study revealed among the significant results between the two groups of doctors, government doctors are better with respect to their type of organization on the dimensions of overall PsyCap and its dimensions. This understanding of PsyCap profile in doctors will help them to identify and work on their potential human strength and foster their professional life.

\section{References}

[1] Avey, James B., et al. "Impact of positive psychological capital on employee wellbeing over time." Journal of occupational health psychology 15.1 (2010): 17

[2] Avey, James B., Fred Luthans, and Susan M. Jensen. "Psychological capital: A positive resource for combating employee stress and turnover." Human resource management48.5 (2009): 677-693.

[3] Choubisa, Rajneesh. "POB: A Comparative Analysis Of Positive Psychological Capital Amongst Public \& Private Sector Employees." All India Management Association Journal of Management and Research 3.3/4 (2009).

[4] Dello Russo, Silvia, and Petya Stoykova. "Psychological capital intervention (PCI): A replication and extension." Human Resource Development Quarterly 26.3 (2015): 329-347.

[5] Demerouti, Evangelia, and Arnold B. Bakker. "The job demands-resources model: Challenges for future research." $S A$ Journal of Industrial Psychology 37.2 (2011): 01-09.

[6] Eid, Jarle, et al. "Leadership, psychological capital and safety research: Conceptual issues and future research questions." Safety science 50.1 (2012): 55-61.

[7] Ertosun, Öznur Gülen, et al. "Positive psychological capital development: a field study by the Solomon four group design." International Business Research 8.10 (2015): 102.

[8] Everly, George, George Everly III, and Douglas Strouse. The Secrets of Resilient Leadership: When Failure Is Not an Option... Six Essential Characteristics for Leading in Adversity. Diamedica, 2011.

[9] Fredrickson, Barbara L. "The role of positive emotions in positive psychology: The broaden-and-build theory of positive emotions." American psychologist 56.3 (2001): 218.

[10] Fredrickson, Barbara. Positivity. Harmony, 2009.

[11] Kivimäki, Mika, et al. "Factors underlying the effect of organisational downsizing on health of employees: longitudinal cohort study." Bmj 320.7240 (2000): 971-975.

[12] Llewellyn, David J., et al. "Self-efficacy, risk taking and performance in rock climbing." Personality and Individual Differences 45.1 (2008): 75-81.

[13] Liu, Li, et al. "The mediating role of psychological capital on the association between occupational stress and depressive symptoms among Chinese physicians: a cross-sectional study." BMC public health 12.1 (2012): 219.

[14] Luthans, Fred. "The need for and meaning of positive organizational behavior." Journal of organizational behavior (2002): 695-706.

[15] Luthans, Fred, and Carolyn M. Youssef. "Human, social, and now positive psychological capital management: Investing in people for competitive advantage." (2004).

[16] Luthans, Fred, Steve Norman, and Larry Hughes. "Authentic leadership." Inspiring leaders (2006): 84-104.

[17] Luthans, Fred, et al. "Positive psychological capital: Measurement and relationship with performance and satisfaction." Personnel psychology 60.3 (2007): 541-572.

[18]Luthans, Fred, Carolyn M. Youssef, and Bruce J. Avolio. Psychological capital: Developing the human competitive edge. Oxford: Oxford University Press, 2007.

[19] Luthans, Fred, et al. "The mediating role of psychological capital in the supportive organizational climate- employee performance relationship." Journal of organizational behavior29.2 (2008): 219238.

[20]Luthans, Brett C., Kyle W. Luthans, and James B. Avey. "Building the leaders of 
tomorrow: The development of academic psychological capital." Journal of Leadership \& Organizational Studies 21.2 (2014): 191-199.

[21]21.Peterson, Suzanne J., Benjamin M. Galvin, and Donald Lange. "CEO servant leadership: Exploring executive characteristics and firm performance." Personnel Psychology65.3 (2012): 565-596.

[22] Shahnawaz, M. G., and Md Hassan Jafri. "Psychological capital as predictors of organizational commitment and organizational citizenship behaviour." Journal of the Indian Academy of Applied Psychology 35 (2009): 78-84.

[23] Sin, Nancy L., and Sonja Lyubomirsky. "Enhancing well-being and alleviating depressive symptoms with positive psychology interventions: A practicefriendly meta-analysis." Journal of clinical psychology 65.5 (2009): 467-487.

[24] Snyder, C. Richard, ed. Handbook of hope: Theory, measures, and applications. Academic press, 2000.

[25] Sweetman, David, et al. "Relationship between positive psychological capital and creative performance." Canadian Journal of Administrative Sciences/Revue Canadienne des Sciences de l'Administration 28.1 (2011): 4-13.

[26] Youssef-Morgan, Carolyn M., and Fred Luthans. "Psychological capital and wellbeing." Stress and Health 31.3 (2015): 180188 . 